\title{
ANALISIS PENUMBUKAN BOLA BAJA TERHADAP MATERIAL BUTIRAN DALAM SILINDER BERPUTAR
}

\author{
Nur Faizin ${ }^{1, a)}$, Lilik Hendrajaya ${ }^{2, b)}$, Sparisoma Viridii, ${ }^{3, c)}$, Muziibu Alfisyah ${ }^{4)}$ \\ 1,2,3Institut Teknologi Bandung, Jl. Ganesha No. 10, Bandung40132 \\ 4Process Engineer, PT. Indocement Tunggal Prakarsa, Tbk. Plant Palimanan Cirebon

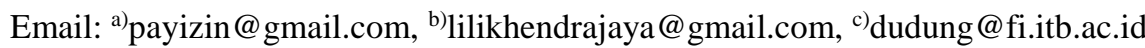

\begin{abstract}
Abstrak
Tumbukan antara bola baja dengan material dimanfaatkan dalam proses penghancuran material butiran. Proses penghancuran tersebut terjadi di dalam silinder yang dinamakan dengan raw mill. Tabung ini diisi dengan bola baja dengan ukuran $6,5 \mathrm{~mm}$ dan diputar pada porosnya. Akibat perputaran tersebut dapat menghasilkan beberapa mode gerak. Mode gerak yang diinginkanadalah mode cataracting dan cascading. Kedua mode gerak ini sangat mendukung dalam proses penghancuran dan penghalusan material. Penelitian dilakukan dengan membuat miniatur raw millyang berupa silinder yang berjari-jari $40 \mathrm{~cm}$ dengan tebal $3 \mathrm{~cm}$. Perbandingan antara miniatur raw milldengan sesungguhnya adalah 1:13,75. Dinding silinder dibentuk bergerigi dengan ketinggian gerigi $4 \mathrm{~mm}$. Data yang diambil yaitu jumlah putaran silinder dan massa butiran material yang diumpankan ke dalam silinder. Data tersebut digunakan untuk estimasi energi rata-rata penumbukan dari bola baja terhadap material.
\end{abstract}

Kata-kata kunci: bola baja, cataracting, cascading.

\begin{abstract}
The collision between the steel balls to the material used in the process of destruction of the granular material. The destruction process occurs in the cylinder whose called the raw mill. This tube is filled with steel balls with a size of $6,5 \mathrm{~mm}$ and rotated on its axis. As a impact of the rotation can produce some modes of motion. The desired motion mode is cataracting and cascading. Both modes of motion are very supportive in the process of crushing and refining material. Research carried out by making a miniature raw mill in the form of a cylinder with radius $40 \mathrm{~cm}$ and $3 \mathrm{~cm}$ of thickness. The comparison between the raw mill with a real miniature is $1: 13,75$. Serrated cylindrical wall formed with a height of $4 \mathrm{~mm}$ serrations. The data was taken are the number of dials and granular mass of material that is dive into the cylinder. The data is used to estimate the average energy comminuting of steel balls against the material.
\end{abstract}

Keywords: steel balls, cataracting, cascading.

\section{PENDAHUluaN}

Pergerakan material butiran dalam suatu tabung silinder merupakan salah satu contoh fenomena fisika klasik. Salah satu industri yang memanfaatkan pergerakan material tersebut adalah industri semen. Dalam industri semen, material di dalam suatu silinder yang berputar digunakan untuk proses penghancuran dan penghalusan material hasil tambang. Silinder putar dalam proses ini disebut sebagai raw mil.

Prinsip kerja dari raw mill yaitu suatu tabung yang diletakkan secara horizontal diputar pada porosnya sehingga bola baja yang ada di dalam tabung tersebut akan mengalami pergerakan. Bola baja yang 
bergerak tersebut akan mengalami beberapa mode gerak diantaranya slipping, slumping, rolling, cascading, cataracting, dan centrifuging. Mode gerak dari bola baja tersebut dipengaruhi oleh beberapa faktor diantaranya: kecepatan angular silinder, jumlah bola baja, dan gaya interaksi antara bola baja terhadap dinding silinder.

Dalam penelitian ini mode gerak bola bajayang diinginkan adalah cataracting dan cascading. Kedua mode gerak tersebut sangat mendukung dalam proses penghancuran dan penghalusan material. Hasil dari penghancuran material selanjutnya disaring dengan ayakan 225 mesh. Persentase material yang lolos dari ayakan tersebut dijadikan sebagai parameter optimal dan kurang optimalnya proses penghancuran material.

\section{METODE PENELITIAN}

Raw mill dalam industri semen merupakan salah satu alat yang berbentuk silinder yang digunakan sebagai wadah material dan bola baja. Cara kerja dari raw mill yaitu material bergerak bersama-sama dengan bola baja dengan memanfaatkan tumbukan dan gerusan dari bola baja tersebut. Produk dari raw mill mempunyai ukuran sekitar $90 \mu \mathrm{m}$.

Dinding bagian dalam (shell) dari raw mill didesain sedemikian rupa agar proses penghancuran dan penghalusan material lebih efektif. Shell dibentuk dari susunan sirip (lifter). Model shell bermacammacam diantaranya Rib liner, Lorain liner, Step liner, dan Wave liner [1].

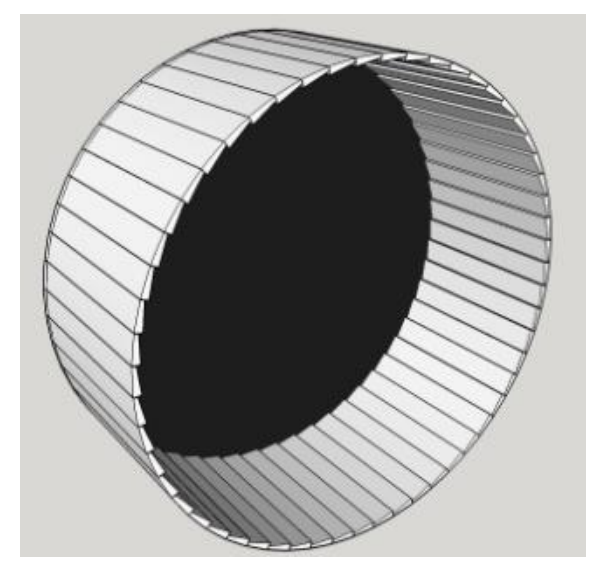

Gambar 1. Desain silinder dengan model lifter

Bentuk sirip dalam raw mill mempengaruhi efektivitas gerak bola baja. Sirip dalam silinder didesain sedemikian rupa, hal ini bertujuan untuk mempermudah terjadinya mode gerak cataracting. Dengan adanya sirip ini, kecepatan rotasi yang dibutuhkan untuk menghasilkan mode cataracting relatif kecil. Beberapa desain telah dikembangkan untuk memperoleh optimasi energi yang paling efisien.Energi ini merupakan energi minimum yang digunakan untuk menghasilkan mode gerak cataracting. 


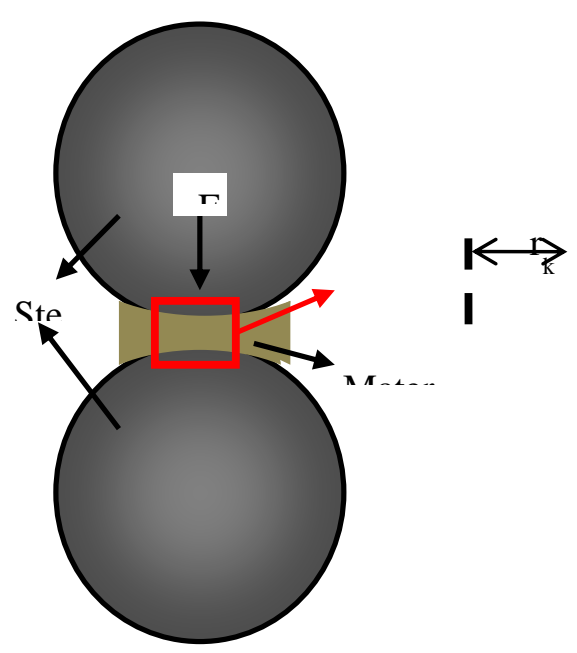

Gambar 2. Bentuk penumbukan bola baja.

Bola baja yang digunakan dalam industri semen memiliki ukuran minimal $35 \mathrm{~mm}$. Karena ukuran bola tersebut relatif besar maka dapat digolongkan sebagai material granular. Syarat disebut material granular jika ukuran material lebih dari $1 \mu \mathrm{m}$ [2]. Bola baja digunakan untuk media penghancur dan penghalus material dalam raw mill.

Tinjauan fisika dalam proses penghancuran dan penghalusan material melibatkan dua gaya yaitu gaya tekan dan gaya geser. Tekanan yang diberikanterhadap material yang ditumbuk adalah

$$
P=\frac{1}{\pi} \sum_{i=1}^{n} \frac{F_{i}}{r_{k, i}^{2}}
$$

dimana $F_{i}$ adalah gaya tekan bola baja dan $r_{k}$ adalah radius kontak [3]. Sedangkan energi spesifik penumbukan dari bola dapat dituliskan pada persamaan berikut,

$$
E_{s}=\frac{m_{b}}{2} \sum_{i=1}^{n} v_{i}^{2}
$$

dimana mb adalah massa bola baja dan vi adalah kecepatan bola baja ke-j, dan ni adalah banyaknya bola baja [3].

Dalam industri semen mode yang sangat bermanfaat adalah cataracting. Mode ini sangat diharapkan karena memberikan impact yang maksimal dibanding mode-mode yang lain. Setiap mode gerak ini memiliki bentuk bed yang berbeda-beda. Adanya transisi syarat batas, akan menghasilkan mode gerak dari bola baja tersebut.

Untuk kasus material dalam silinder yang berputar pada sumbu aksial, bilangan Froude dapat didefinisikan sebagai perbandingan antara gaya sentripetal dengan gaya berat material.

$$
F_{r}=\frac{\omega^{2} r}{g}
$$

Dimana $F_{r}$ adalah bilangan Froude, $\omega$ adalah kecepatan sudut drum, $r$ adalah jari-jari drum, dan $g$ adalah percepatan gravitasi [4]. 


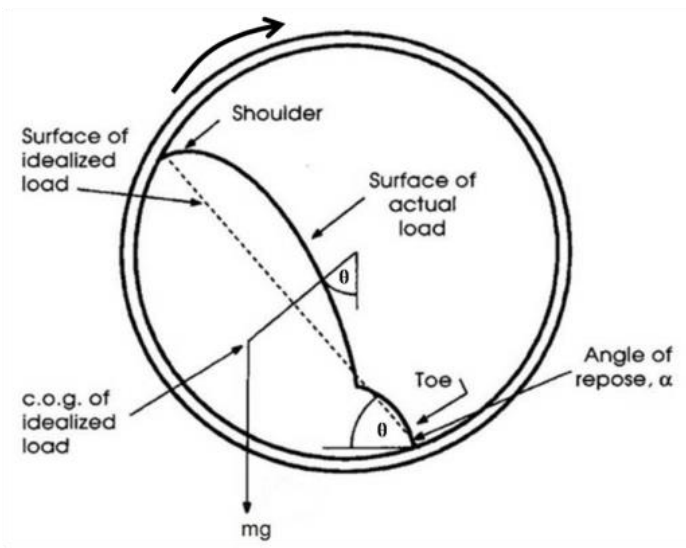

Gambar 3. Mode gerak material dalam silinder [6].

Dalam mode gerak material dalam drum berputar dikenal dua titik yaitu titik toe dan shoulder. Titik toe merupakan titik terendah material saat silinder diputar pada sumbu aksial. Sedangkan titik shoulder adalah titik tertinggi material di dalam silinder saat mulai terlepas dari dinding. Titik toe dan shoulder dipandang dari garis vertikal $\left(0^{\circ}\right)[5]$.

Titik toe dan shoulder timbul akibat pergerakan material. Adanya perpindahan material saat silinder berputar, momen gaya yang ditimbulkan oleh material tersebut adalah

$$
\tau=m g r_{m} \sin \theta \text {. }
$$

dimana $r_{m}$ adalah jarak pusat massa material terhadap titik pusat silinder.

Posisi titik shoulder dipengaruhi oleh kecepatan sudut dari silinder. Semakin tinggi kecepatan silinder maka posisi titik shoulder semakin tinggi juga. Silinder yang berisi bola baja memiliki kecepatan kritis yang berbeda bergantung ukuran silinder dan bola baja pengisi. Secara umum kecepatan kritis dari silinder dapat dituliskan sebagai berikut [1],

$$
\omega_{c}=\frac{42,3}{\sqrt{D-d}},
$$

dimana $D$ adalah jari-jari silinder dan $d$ adalah jari-jari bola baja. Pada proses penghancuran material di dalam silinder, umumnya menggunakan kecepatan kritis yaitu $65-82 \%$, kadangkala ada juga yang menggunakan kecepatan kritis $90 \%$ [7].

Eksperimen dilakukan dengan skala laboratorium. Diameter bola baja yang digunakan adalah 6,5 $\mathrm{mm}$. Sedangkan diameter silinder dalam eksperimen adalah $40 \mathrm{~cm}$. Dalam penelitian ini material yang digunakan sebagai sampel adalah produk dari raw mill yang diperoleh dari pabrik semen PT. Indocement Tunggal Prakarsa. Tbk. Sampel tersebut dibentuk menjadi butiran dengan ukuran rata-rata $0,8 \mathrm{~cm}$. Butiran dari sampel ini dikeringkan dahulu sebelum dicampur dengan bola baja untuk dihaluskan. Pengeringan butiran dimaksudkan agar tidak ada debu hasil penghancuran yang menempel pada bola baja ataupun dinding silinder. Butiran yang telah dihancurkan selanjutnya disaring menggunakan ayakan dengan ukuran 225 mesh.

\section{HASIL DAN PEMBAHASAN}

Hasil eksperimen diperoleh dengan memvariasikan jumlah butiran material dan jumlah putaran dari silinder. Dalam penelitian ini massa bola baja dibuat konstan yaitu 500 gram. Pada eksperimen pertama massa butiran dibuat tetap juga yaitu 50 gram. Setelah dilakukan variasi putaran, diperoleh hasil seperti ditunjukkan oleh Tabel 1. Diketahui bahwa jumlah material yang lolos saringan semakin besar apabila jumlah putaran silinder diperbesar. Untuk memperoleh gambaran yang lebih jelas Tabel 1 dapat disajikan dalam bentuk plot seperti yang ditunjukkan pada Gambar 4. 
Tabel 1. Variasi putaran silinder dan material yang lolos saringan.

\begin{tabular}{|c|c|c|}
\hline $\begin{array}{c}\text { Material } \\
\text { (gram) }\end{array}$ & $\begin{array}{c}\text { Jumlah } \\
\text { putaran }\end{array}$ & Lolos $(\%)$ \\
\hline 50 & 5 & 0,22 \\
\hline 50 & 10 & 1,74 \\
\hline 50 & 20 & 4,02 \\
\hline 50 & 25 & 6,42 \\
\hline 50 & 35 & 10,02 \\
\hline 50 & 45 & 10,3 \\
\hline 50 & 60 & 12,6 \\
\hline
\end{tabular}

Gambar 4 menunjukkan adanya perubahan jumlah material yang lolos. Semakin tinggi jumlah putaran maka jumlah material yang lolos dari saringan semakin banyak. Jumlah material yang lolos dari saringan akibat proses penghancuran dipengaruhi oleh peristiwa penumbukan bola baja terhadap material butiran.

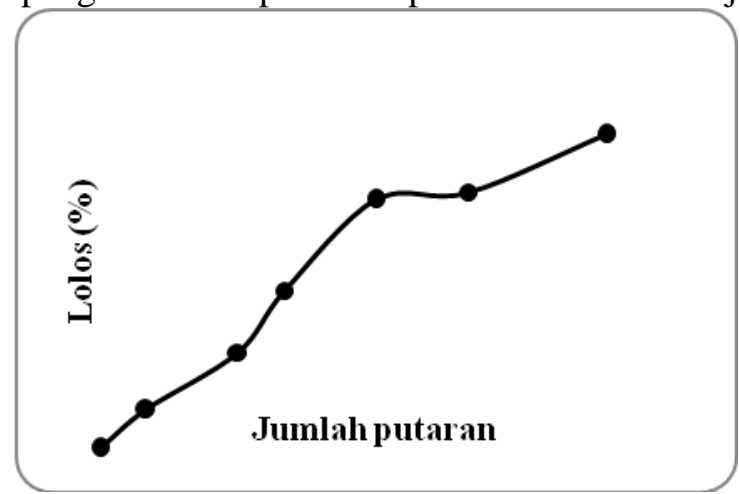

Gambar 4.Variasi jumlah putaran vs material yang lolos 225 mesh.

Jika bola baja menumbuk material terus menerus maka material akan hancur. Banyaknya putaran silinder dapat mempengaruhi peluang terjadinya tumbukan antara bola baja dengan material.Sehingga semakin banyak jumlah putaran silinder maka jumlah tumbukan bola baja dengan butiran material semakin besar juga.

Selain jumlah tumbukan antar material, faktor lain adalah nilai koefisien restitusi material lebih kecil dibanding dengan bola baja.Dalam proses penghancuran material nilai koefisien restitusi yang tinggi sangat dibutuhkan agar diperoleh hasil grinding yang baik [8].

Percobaan selanjutnya adalah variasi massa butiran yang diumpan ke dalam silinder. Dalam perlakuan ini massa bola baja dibuat konstan yaitu 500 gram dan jumlah putaran yang digunakan adalah 35 putaran. Plot antara persentase material yang lolos saringan. Hasil dari percobaan ini disajikan pada tabel berikut.

Tabel 2. Variasi massa material dan material yang lolos saringan.

\begin{tabular}{|c|c|c|}
\hline $\begin{array}{c}\text { Jumlah } \\
\text { putaran }\end{array}$ & $\begin{array}{c}\text { Massa } \\
\text { material } \\
\text { (gram) }\end{array}$ & Lolos (\%) \\
\hline 35 & 20 & 39,65 \\
\hline 35 & 40 & 16,8 \\
\hline 35 & 50 & 14,04 \\
\hline 35 & 60 & 8,38 \\
\hline 35 & 80 & 5,21 \\
\hline 35 & 100 & 1,94 \\
\hline
\end{tabular}

Massa material yang dimasukkan ke dalam silinder sangat mempengaruhi jumlah material yang lolos saringan. Hal itu ditunjukkan oleh persentase material yang lolos, semakin besar material yang 
dimasukkan maka persentase material yang lolos semakin kecil. Untuk lebih jelasnya Tabel 1 dapat digambarkan dalam bentuk plot antara persentase material yang lolos saringan terhadap massa material.

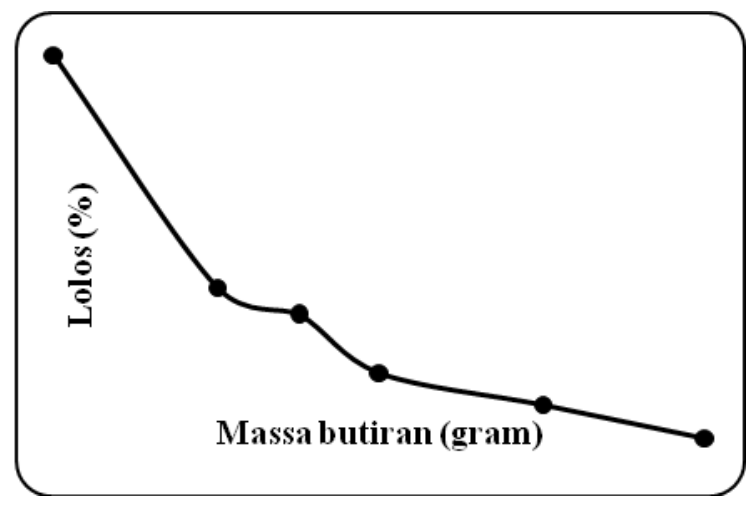

Gambar 5.Variasi massa butiran vs material yang lolos 225 mesh.

Persentase massa butiran terhadap massa bola baja dapat mempengaruhi proses grinding. Gambar 5 menunjukkan bahwa proses penghancuran material kurang baik jika massa butiran diperbesar. Hal ini terjadi akibat adanya faktor redaman dari material terhadap bola baja saat menumbuk. Semakin besar massa butiran material yang diumpankan maka faktor redaman terhadap bola baja semakin besar pula.

Saat massa butiran 20 gram atau 4\% dari massa bola baja diperoleh bahwa jumlah material yang lolos saringan paling tinggi dibanding dengan massa butiran yang lebih banyak. Hal ini dikarenakan proses penumbukan terhadap material lebih optimal dibandingkan dengan massa butiran yang lebih besar.

\section{KESIMPULAN}

Dari hasil penelitian ini dapat diketahui faktor-faktor yang mempengaruhi proses penumbukan material antara lain jumlah putaran silinder dan massa butiran yang diumpan. Jika jumlah putaran diperbesar maka proses grinding semakin baik, hal itu ditunjukkan dengan semakin tingginya persentase material yang lolos dari saringan. Faktor redaman yang ditimbulkan oleh jumlah massa butiran dapat mempengaruhi proses grinding.

\section{UCAPAN TERIMAKASIH}

Saya ucapkan terimakasih kepada PT. Indocement Tunggal Prakarsa. Tbk yang telah memberikan kesempatan penulis untuk observasi lapang dan pemberian sampel penelitian, segenap anggota Bengkel Bhakti yang telah membantu proses pembuatan alat mill.

\section{DAFTAR ACUAN}

[1] Wills, B. A., \& Napier-Munn, T. (2015). Wills' mineral processing technology: an introduction to the practical aspects of ore treatment and mineral recovery. Butterworth-Heinemann.

[2] de Gennes, P. G. (1999). Granular matter: a tentative view. Reviews of modern physics, 71(2), S374.

[3] Sheng-Yong, L., Qiong-Jing, M., Zheng, P., Xiao-Dong, L., \& Jian-Hua, Y. (2012). Simulation of ball motion and energy transfer in a planetary ball mill.Chinese Physics B, 21(7), 078201.

[4] Santomaso, A. C., Ding, Y. L., Lickiss, J. R., \& York, D. W. (2003). Investigation of the granular behaviour in a rotating drum operated over a wide range of rotational speed. Chemical Engineering Research and Design, 81(8), 936-945.

[5] Lameck, N. N. S. (2006). Effects of grinding media shapes on ball mill performance (Doctoral dissertation). 
[6] Moys, M. H. (1993). A model of mill power as affected by mill speed, load volume, and liner design. JOURNAL-SOUTH AFRICAN INSTITUTE OF MINING AND METALLURGY, 93, 135-135.

[7] King, R. P. (2012). Modeling and simulation of mineral processing systems. Elsevier.

[8] Jayasundara, C. T., Yang, R. Y., Yu, A. B., \& Curry, D. (2008). Discrete particle simulation of particle flow in IsaMill-effect of grinding medium properties. Chemical Engineering Journal, 135(1), 103-112. 
